\section{Phylogenetic relationships of three amino-acid-utilizing anaerobes, Selenomonas acidaminovorans, 'Selenomonas acidaminophila' and Eubacterium acidaminophilum, as inferred from partial 165 rDNA nucleotide sequences and proposal of Thermanaerovibrio acidaminovorans gen. nov., comb. nov. and Anaeromusa acidaminophila gen. nov., comb. nov.}

Sandra Baena, ${ }^{1,2}$ Marie-Laure Fardeau, ${ }^{1}$ T. H. S. Woo, ${ }^{3}$ Bernard Ollivier, ${ }^{1}$ Marc Labat ${ }^{1}$ and Bharat K. C. Patel ${ }^{3}$
1 Laboratoire ORSTOM de Microbiologie des Anaérobies, Université de Provence, CESB-ESIL Case 925, 163 Avenue de Luminy, 13288 Marseille Cedex 9, France

2 Departamento de Biologia, Pontificia Universidad Javeriana, POB 56710, SantaFe de Bogota, Colombia

3 School of Biomolecular and Biomedical Sciences, Faculty of Science, Griffith University, Brisbane, Queensland 4111, Australia

\author{
Author for correspondence: Bharat K. C. Patel. Tel: +61 417726671 . Fax: +61 738757656. \\ e-mail: bharat@genomes.sci.gu.edu.au
}

165 rRNA gene sequences of three previously described amino-acid-fermenting anaerobes, Selenomonas acidaminovorans, 'Selenomonas acidaminophila' and Eubacterium acidaminophilum, were determined. All three were found to cluster within the Clostridium and related genera of the subphylum of the Gram-positive bacteria. The thermophile, S. acidaminovorans, formed an individual line of descent and was equidistantly placed between Dethiosulfovibrio peptidovorans and Anaerobaculum thermoterrenum (similarity of $\mathbf{8 5} \%$ ), both of which also form single lines of descent. 'S. acidaminophila' was related to Clostridium quercicolum, a member of cluster IX, with a similarity of $90 \%$, whereas E. acidaminophilum was closely related to Clostridium Iitorale (similarity of $96 \%$ ) as a member of cluster XI. Based on the phylogenetic data presented in this report and the phenotypic descriptions of these bacteria published previously, it is recommended that $S$. acidaminovorans be transferred to a new genus, Thermanaerovibrio gen. nov., as Thermanaerovibrio acidaminovorans comb. nov. and 'Selenomonas acidaminophila' be transferred to a new genus, Anaeromusa gen. nov., as Anaeromusa acidaminophila comb. nov. Though the transfer of $E$. acidaminophilum to a new taxon is justified, this is not recommended until the taxonomic status of all the members of cluster XI has been reviewed.

Keywords: amino acids, 16S rRNA analysis, Selenomonas, Eubacterium

\section{INTRODUCTION}

The trait of peptide and amino acid utilization as carbon, nitrogen and energy sources is distributed

The GenBank accession numbers for the 165 rRNA gene sequences of Thermanaerovibrio acidaminovorans, Anaeromusa acidaminophila and Eubacterium acidaminophilum are AF071414, AF071415 and AF071416, respectively. amongst many anaerobic bacteria. This trait has been widely investigated in saccharolytic clostridia (McInerney, 1988; Paster et al., 1993; Attwood et al., 1998) but not in asaccharolytic clostridia (Nanninga et al., 1987; Guangsheng et al., 1992; Zindel et al., 1988). Published data indicate that such bacteria may play an important role in the cycling of nitrogen, sulfur and carbon in diverse ecosystems such as the rumen 
(Attwood et al., 1998), human colon (Smith \& Macfarlane, 1997) and waste digesters (Siebert \& Toerien, 1969). We have recently initiated studies on understanding the role of obligate amino-acidoxidizing and/or -fermenting anaerobic bacteria in dairy waste digesters. We were expecting to isolate new taxa from our studies and consequently, we searched the literature to identify and complete gaps in the taxonomy of amino-acid-degrading anaerobic bacteria. During this process, we identified only three such isolates, namely Selenomonas acidaminovorans (Guangsheng et al., 1992), 'Selenomonas acidaminophila' (Nanninga et al., 1987) and Eubacterium acidaminophilum (Zindel et al., 1988), which had all been validated using phenotypic rather than phylogenetic criteria. Our intention was to complete a phylogenetic analysis based on 16S rRNA gene sequences so that this data could then be used for comparison with our new isolates. The taxonomic position of the three isolates is reported.

\section{METHODS}

Source and culture of strains. S. acidaminovorans strain Su883 ${ }^{\mathrm{T}}$ (DSM 6589 $)$, 'S. acidaminophila' strain Dkglu16 ${ }^{\mathrm{T}}$ (DSM $3853^{\mathrm{T}}$ ) and $E$. acidaminophilum strain al-2 ${ }^{\mathrm{T}}$ (DSM $3953^{\mathrm{T}}$ ) were purchased from DSMZ (Deutsche Sammlung von Mikroorganismen und Zellkulturen, Braunschweig, Germany), and were grown on media and under conditions described previously (Guangsheng et al., 1992; Nanninga et al., 1987; Zindel et al., 1988).

DNA extraction and amplification of 16S rRNA gene. DNA was extracted from the isolates as described previously (Redburn \& Patel, 1993; Andrews \& Patel, 1996). The universal primers Fdl and Rdl were used to obtain a PCR product of approximately $1.5 \mathrm{~kb}$ corresponding to base positions 8-1542 based on Escherichia coli numbering of the 16S rDNA (Winker \& Woese, 1991). A $50 \mu$ l reaction mix contained $1-20 \mathrm{ng}$ genomic DNA, $1 \mu \mathrm{M}$ each primer, $5 \mu \mathrm{l}$ $10 \times$ buffer, $200 \mu \mathrm{M}$ dNTP, $3.5 \mathrm{mM} \mathrm{MgCl}_{2}$ and $2.5 \mathrm{U}$ Taq polymerase (Promega). PCR was carried out by an initial denaturation at $94^{\circ} \mathrm{C}$ for $7 \mathrm{~min}$, then 29 cycles of annealing at $55^{\circ} \mathrm{C}$ for $2 \mathrm{~min}$, extension at $72^{\circ} \mathrm{C}$ for $4 \mathrm{~min}$, denaturation at $94{ }^{\circ} \mathrm{C}$ for $1 \mathrm{~min}$ and finally an extension cycle of $55^{\circ} \mathrm{C}$ for $2 \mathrm{~min}$ and $72^{\circ} \mathrm{C}$ for $20 \mathrm{~min}$. PCR products were purified with a QIAquick kit (Qiagen). DNA concentration of purified PCR product was estimated by comparison with the Low Mass Ladder (Gibco-BRL) on an agarose gel containing ethidium bromide.

Direct sequencing of PCR products. QIAquick-purified PCR products were sequenced using the ABI PRISM Dye Terminator Cycle Sequencing kit containing AmpliTaq FS DNA polymerase and an ABI $373 \mathrm{~A}$ sequencer. A $10 \mu \mathrm{l}$ reaction mix contained $35 \mathrm{ng}$ PCR product, $4 \mu \mathrm{l}$ cycle sequencing reaction mix, $3 \cdot 2 \mathrm{pmol}$ primer (Andrews \& Patel, 1996) and $2.5 \mu \mathrm{g}$ BSA. Thermal cycling was carried out using a RapidCycler (Idaho Technology) at a temperature transition slope of 2 , an initial denaturation of $94^{\circ} \mathrm{C}$ for $15 \mathrm{~s}$, then 25 cycles of denaturation at $94^{\circ} \mathrm{C}$ for $0 \mathrm{~s}$, annealing at $50{ }^{\circ} \mathrm{C}$ for $10 \mathrm{~s}$ and extension at $60^{\circ} \mathrm{C}$ for $3 \mathrm{~min}$.

Sequence alignments and phylogenetic inferences. The new sequence data that were generated were aligned and almost full-length consensus 16S rRNA gene sequences were assembled and checked for accuracy manually using the alignment editor ae2 (Maidak et al., 1996). These were compared with other sequences in the GenBank database (Benson et al., 1993) using BLAST (Altschul et al., 1997), and sequences from the Ribosomal Database Project, version 5.0 using SIMILARITY_RANK and SUGGEST_TREE (Maidak et al., 1996). Reference sequences most related to our newly generated sequences were extracted from these databases and aligned. Positions of sequence and alignment uncertainty were omitted from the analysis. Pairwise evolutionary distances based on 1003 unambiguous nucleotides were computed using DNADIST (Jukes \& Cantor option) and neighbour-joining programs that form part of the PHYLIP suite of programs (Felsenstein, 1993). TREECON was used extensively for bootstrap analysis (Van de Peer \& De Wachter, 1993).

\section{RESULTS AND DISCUSSION}

Almost complete 16S rRNA gene sequences comprising 1426, 1530 and 1508 nucleotides, corresponding to $E$. coli positions $14-1540,17-1539$ and $16-1539$ (Winker \& Woese, 1991), were determined for $S$. acidaminovorans, ' $S$. acidaminophila' and $E$. acidaminophilum, respectively. Several phylogenetic trees constructed from representative 16S rRNA sequences of members of the domain Bacteria revealed that the three strains were not related to each other and were clustered as members of the Clostridium and related genera of the subphylum of the Gram-positive bacteria (Fig. 1).

S. acidaminovorans (Guangsheng et al., 1992) and ' $S$. acidaminophila' (Nanninga et al., 1987) are Gramnegative, non-spore-forming curved rods which are motile by means of a tuft of flagella and were assigned to the genus Selenomonas based on these characteristics. However, phylogenetic analysis revealed that the sequence similarity of these two isolates was low $(80 \%)$ and they were therefore not specifically related to each other. The analysis also showed that both isolates were distantly placed from members of the genus Selenomonas with a similarity of only $80 \%$. Therefore, the two isolates cannot be ascribed as members of the genus Selenomonas.

$S$. acidaminovorans was equidistantly placed between Dethiosulfovibrio peptidovorans and Anaerobaculum thermoterrenum (similarity of $85 \%$ ). All three strains shared in common the property of strict anaerobiosis for growth and had curved cell morphology; each member formed an independent line of descent in the vicinity of cluster V (Rees et al., 1997; Magot et al., 1997; Collins et al., 1994). The phylogenetic separation alone is sufficient grounds for proposing that $S$. acidaminovorans be transferred to a new genus but, in addition, the considerable differences in the $\mathrm{G}+\mathrm{C}$ content and phenotypic characteristics amongst $S$. acidaminovorans, $D$. peptidovorans and $A$. thermoterrenum further strengthen the argument for the creation of a new genus (Table 1 ). $S$. acidaminovorans is a thermophilic strain isolated from a sludge sample. 


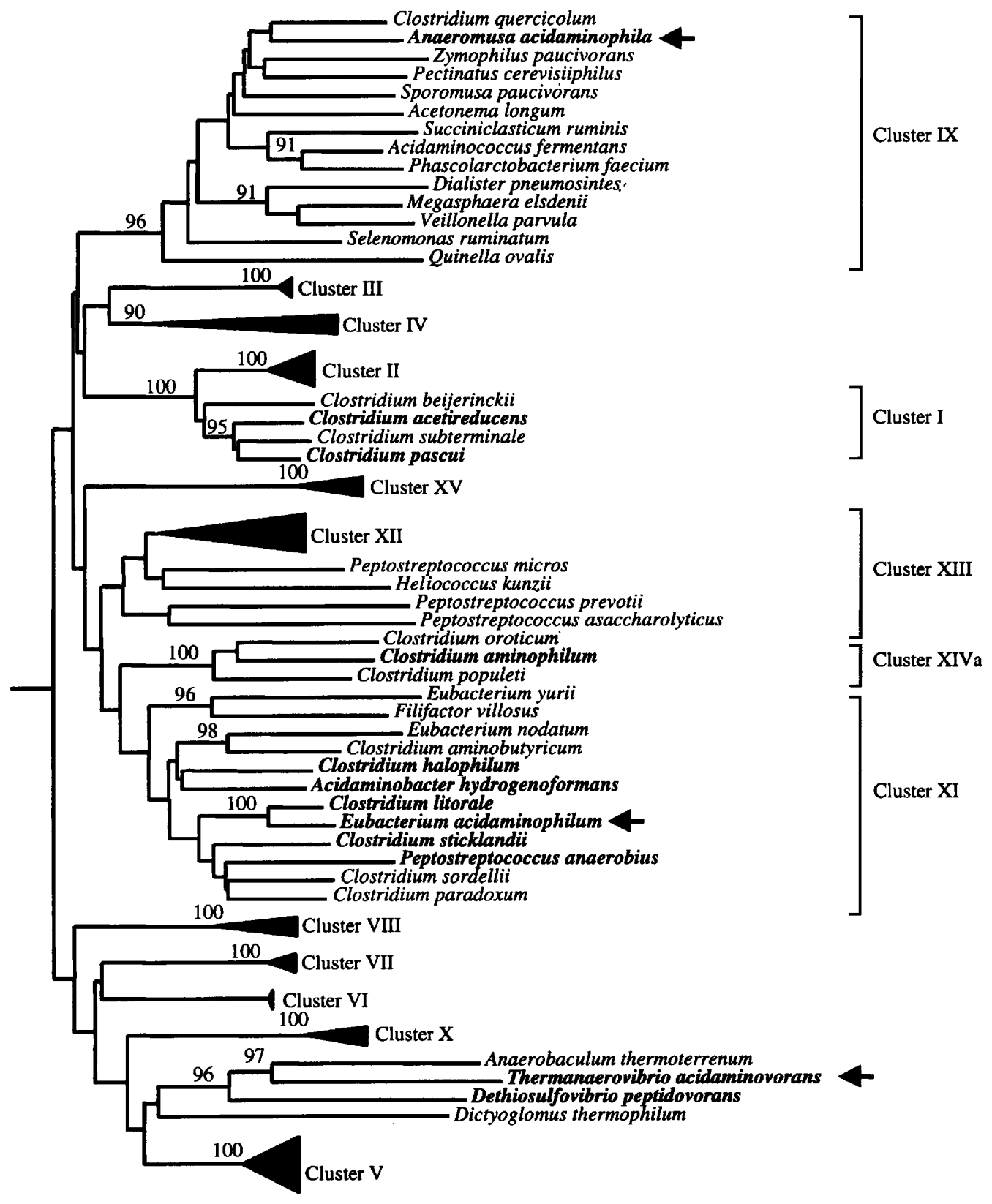

$10 \%$

Fig. 1. Unrooted dendrogram based on $16 \mathrm{~S}$ rRNA sequence data indicating the phylogenetic positions of Thermanaerovibrio acidaminovorans strain DSM $6589^{\top}$ (Selenomonas acidaminovorans), Anaeromusa acidaminophila strain DSM $3853^{\top}$ ('Selenomonas acidaminophila') and Eubacterium acidaminophilum (strain DSM 3953') within the radiation of representatives of the low-G + C-containing Gram-positive bacteria. The proposed new taxa studied in this paper are indicated by arrows and names of various amino-acid-degrading bacteria are indicated in bold type. All the sequences used in the analysis, with the exception of Anaerobaculum thermoterrenum, Dethiosulfovibrio peptidovorans and Acidaminobacter hydrogenoformans (GenBank nos U50711, U52817 and AF016691, respectively) and Clostridium acetireducens and Clostridium pascui (EMBL nos X79862 and X96736, respectively), were obtained from the Ribosomal Database Project, version 5.0 (Maidak et al., 1996). Bootstrap values, expressed as a percentage of 100 replications are shown at the branching points. Only values above $90 \%$ were considered significant and therefore reported. Scale bar, 10 nucleotide substitutions per 100 nucleotides.

It has a DNA $\mathrm{G}+\mathrm{C}$ content of $56.5 \mathrm{~mol} \%$ and ferments carbohydrates (e.g. glucose, fructose) and a number of amino acids (e.g. glutamate, histidine). It also oxidizes amino acids in syntrophic association with a hydrogen scavenger (Methanobacterium thermoautotrophicum). A. thermoterrenum is a thermophilic strain isolated from a petroleum reservoir and has a DNA $\mathrm{G}+\mathrm{C}$ content of $44 \mathrm{~mol} \%$. It grows on a range 
Table 1. Distinguishing features of the amino-acid-degrading bacteria Thermanaerovibrio acidaminovorans, Anaeromusa acidaminophila, Clostridium acidaminophila and their closest phylogenetic relatives

Strains: 1, Selenomonas acidaminovorans [proposal to reassign as Thermanaerovibrio acidaminovorans gen. nov., comb. nov. (cluster V)]; 2, Anaerobaculum thermoterrenum; 3, Dethiosulfovibrio peptidovorans; 4, 'Selenomonas acidaminophila' [proposal to reassign as Anaeromusa acidaminophila gen. nov., comb. nov. (cluster IX)]; 5, Clostridium quercicolum; 6, Eubacterium acidaminophilum (to be considered for reassignment as part of the taxonomic revision of members of cluster XI); 7 , Clostridium litorale. Abbreviations: AA, amino acid; P, peptides; A, acetate; Pr, propionate; I-B, isobutyrate; I-V, isovalerate; 2-MB, 2methylbutyrate; Et, ethanol; Am, ammonia, Su, succinate; NR, not reported.

\begin{tabular}{|c|c|c|c|c|c|c|c|}
\hline Character & 1 & 2 & 3 & 4 & 5 & 6 & 7 \\
\hline Habitat & $\begin{array}{l}\text { Methanogenic } \\
\text { digester }\end{array}$ & $\begin{array}{l}\text { Petroleum } \\
\text { reservoir }\end{array}$ & $\begin{array}{l}\text { Oil-producing } \\
\text { well }\end{array}$ & $\begin{array}{l}\text { Anaerobic } \\
\text { digester }\end{array}$ & $\begin{array}{r}\text { Tissue of } \\
\text { oak tree }\end{array}$ & $\begin{array}{l}\text { Black anaerobic } \\
\text { sediment }\end{array}$ & $\begin{array}{l}\text { Marine } \\
\text { sediments }\end{array}$ \\
\hline Rod morphology & Curved & Curved & Curved & Curved & Straight & Straight & Straight \\
\hline Spores & - & - & - & - & + & - & + \\
\hline Flagella & $6-8$, lateral & No & 1-5, lateral & Up to 16 , lateral & Peritrichous & 1, polar to subpolar & $\begin{array}{l}\text { Yes; details not } \\
\text { reported }\end{array}$ \\
\hline $\begin{array}{l}\mathrm{NaCl} \text { required for optimum } \\
\text { growth }\end{array}$ & No & Yes $(1 \%)$ & Yes $(3 \%)$ & No & No & $\mathrm{NR}$ & Yes $(1 \%)$ \\
\hline Growth temperature $\left({ }^{\circ} \mathrm{C}\right)^{*}$ & $55(40-58)$ & 55 & $42(20-45)$ & $38(25-46)$ & $25-30$ & $3236(15-40)$ & $28(13-39)$ \\
\hline Growth $\mathrm{pH}^{*}$ & $6.5-8.1$ & $7 \cdot 0-7 \cdot 6(5 \cdot 5-8 \cdot 6)$ & $7 \cdot 0(5 \cdot 5-8 \cdot 8)$ & $6 \cdot 8-7 \cdot 2(5-8 \cdot 5)$ & NR & $7 \cdot 1-7 \cdot 4(6.5-8.5)$ & $7 \cdot 3(6 \cdot 5-8 \cdot 4)$ \\
\hline $\mathrm{G}+\mathrm{C}(\mathrm{mol} \%)$ & $56 \cdot 5$ & 44 & 56 & 48 & $52-54$ & 44 & 26 \\
\hline Carbohydrates utilized & + & + & - & - & + & - & - \\
\hline P/AA utilized & AA & AA, P & $\mathrm{AA}, \mathrm{P}$ & AA & $\mathrm{NR}$ & AA, P & AA \\
\hline $\begin{array}{l}\text { Sulfur compounds used as } \\
\text { electron acceptors }\end{array}$ & - & $\begin{array}{l}\text { Thiosulfate, } \mathrm{S}^{\circ} \text {, } \\
\text { cystine }\end{array}$ & Thiosulfate, $\mathrm{S}^{\circ}$ & - & - & - & - \\
\hline Fermentation products & $\mathrm{A}, \mathrm{Pr}$ & A & $\begin{array}{l}\text { A, I-V, I-B, 2-MB, } \\
\mathrm{CO}_{2}, \mathrm{H}_{2}\end{array}$ & $\mathrm{~A}, \mathrm{Pr}, \mathrm{Su}$ & $\mathrm{NR}$ & A, Et, $\mathrm{CO}_{2}, \mathrm{H}_{2}, \mathrm{Am}$ & A, B \\
\hline Reference & $\begin{array}{l}\text { Guangsheng } \\
\text { et al. (1992) }\end{array}$ & Rees et al. (1997) & Magot et al. (1997) & $\begin{array}{l}\text { Nanninga et al. } \\
\text { (1987) }\end{array}$ & $\begin{array}{l}\text { Stankewich } \\
\text { et al. (1971) }\end{array}$ & Zindel et al. (1988) & $\begin{array}{l}\text { Fendrich et al. } \\
\text { (1990) }\end{array}$ \\
\hline
\end{tabular}

* Optimum is given; ranges are shown in parentheses.

of carbohydrates, organic compounds, protein extracts and Casamino acids. On the other hand, D. peptidovorans, a mesophilic isolate from an oilfield, has a DNA $\mathrm{G}+\mathrm{C}$ content of $56 \mathrm{~mol} \%$, is an obligate peptide and amino acid degrader that is unable to utilize carbohydrates or oxidize amino acids in the presence of a hydrogen scavenger (Magot et al., 1997). Based on this evidence, we propose to create a new genus, Thermanaerovibrio gen. nov. and transfer $S$. acidaminovorans to the genus as Thermanaerovibrio acidaminovorans gen. nov., comb. nov.

'S. acidaminophila' (Nanninga et al., 1987), which has not yet been formally taxonomically validated, was related to Clostridium quercicolum, a member of cluster IX, with a similarity of $90 \%$. This result alone signifies that ' $S$. acidaminophila' should be accorded genus status. The argument is further strengthened by the numerous phenotypic and genotypic differences between ' $S$. acidaminophila' and $C$. quercicolum (Table 1). ' $S$. acidaminophila', an isolate of an anaerobic digester, is a mesophilic non-spore-former, has a DNA $\mathrm{G}+\mathrm{C}$ content of $48 \mathrm{~mol} \%$ and ferments a very limited range of substrates including glutamate, aspartate, lactate and pyruvate, but not carbohydrates. $C$. quercicolum is also a mesophile but was isolated from oak tree tissue (Stankewich et al., 1971). It forms spores, ferments carbohydrates and has a DNA G +C content of $52-54 \mathrm{~mol} \%$. Based on phylogenetic evidence and the distinct phenotypic characteristics, we propose that a new genus, Anaeromusa gen. nov., be created and that ' $S$. acidaminophila' be transferred to this genus as Anaeromusa acidaminophila gen. nov., comb. nov. The cluster contains a heterogeneous collection of spore-forming and non-spore-forming bacteria, many of which are Gram-negative, but the cluster is a cohesive group at suprageneric level supported by a bootstrap value of $99 \%$ (Collins et al., 1994).

E. acidaminophilum (Zindel et al., 1988) is a member of cluster XI (similarity of 87-96\%) and is most closely related to Clostridium litorale (similarity of $96 \%$ ). There are sufficient phenotypic and genotypic differences between $C$. litorale and E. acidaminophilum to support the notion that they should be designated separate species (Table 1). E. acidaminophilum, a nonsporulating strain isolated from anaerobic mud, has a DNA G + C content of $44 \mathrm{~mol} \%$, oxidizes amino acids if a hydrogen scavenger or chemical electron acceptors are present and ferments serine and glycine. On the other hand, C. litorale (Fendrich et al., 1990) is a halotolerant spore-forming strain, isolated from anoxic marine sediments. It oxidizes amino acids by the Stickland reaction and has a DNA G $+\mathrm{C}$ content of $26 \mathrm{~mol} \%$. Over the past five years, there has been a slow and gradual revision of the taxonomy of the clostridial and non-clostridial members of the low$\mathrm{G}+\mathrm{C}$-containing Gram-positive bacteria phylum. Collins et al. (1994) indicated that cluster XI is a taxonomically heterogeneous group consisting of several sublines of descent. They suggested that all 
members should be incorporated into a single suprageneric family consisting of several genera. $C$. litorale forms an independent line of descent (similarity less than $92 \%$ with other members of the cluster) and hence, according to this suggestion, a new genus should be created to accommodate $C$. litorale and subsequently $E$. acidaminophilum. However, given that this cluster contains numerous other amino acid utilizers (Fig. 1) and other strains have still to be analysed both for phylogeny and the ability to degrade amino acids, it would be prudent to wait until a more comprehensive overhaul of this group has been discussed formally before E. acidaminophilum is reassigned as a new taxon.

\section{Description of Thermanaerovibrio gen. nov.}

Thermanaerovibrio (Therm.an.ae.ro.vib'ri.o. Gr. adj. thermos hot; Gr. pref. an not; Gr. n. aer air; M.L. masc. n. vibrio that vibrates; M.L. masc. n. Thermanaerovibrio a thermophilic vibrating anaerobe).

Strictly anaerobic curved cells with rounded ends. Motile and Gram-negative. Non-spore-former. Uses amino acids and carbohydrates. The type species is Thermanaerovibrio acidaminovorans comb. nov.

\section{Description of Thermanaerovibrio acidaminovorans (Guangsheng, Plugge, Roelofsen, Houwen and Stams 1992) comb. nov.}

Thermanaerovibrio acidaminovorans (a.ci.dam.in. $\mathrm{o}^{\prime}$ vor.ans. M.L. neut. n. acidum acid; M.L. neut. n. aminum amine; L. part. adj. vorans devouring; M.L. part. adj. acidaminovorans amino-acid-digesting).

The description of Thermanaerovibrio acidaminovorans comb. nov. is identical to that proposed for Selenomonas acidaminovorans (Guangsheng, Plugge, Roelofsen, Houwen and Stams 1992). The type strain is DSM $6589^{\mathrm{T}}$.

\section{Description of Anaeromusa gen. nov.}

Anaeromusa (An.ae.ro'mu.sa. L. v. Gr. pref. an not; Gr. n. aer air; M.L. n. musa a banana; M.L. fem. n. Anaeromusa an anaerobic banana).

Strictly anaerobic Gram-negative curved rods. Nonspore-former. Ferments and oxidizes amino acids. The type species is Anaeromusa acidaminophila comb. nov.

\section{Description of Anaeromusa acidaminophila (Nanninga, Drent and Gottschal 1987) comb. nov.}

Anaeromusa acidaminophila (a.ci.dam.in.o'phi.la. M. L. neut. n. acidum acid; M.L. neut. n. aminum amine; Gr. adj. philus loving; M.L. part. adj. acidaminophila amino-acid-loving).
The description of Anaeromusa acidaminophila comb. nov. is identical to that proposed for 'Selenomonas acidaminophila' (Nanninga, Drent and Gottschal 1987). The type strain is DSM $3853^{\mathrm{T}}$.

\section{REFERENCES}

Altschul, S. F., Madden, T. L., Schäffer, A. A., Zhang, J., Zhang, Z. Miller, W. \& Lipman, D. J. (1997). Gapped BLAST and PSI-BLAST: a new generation of protein database search programs. Nucleic Acids Res 25, 3389-3402.

Andrews, K. T. \& Patel, B. K. C. (1996). Fervidobacterium gondwanense sp. nov., a new thermophilic anaerobic bacterium isolated from nonvolcanically heated geothermal waters of the Great Artesian Basin of Australia. Int $J$ Syst Bacteriol 46, 265-269.

Attwood, G. T., Klieve, A. V., Ouwerkerk, D. \& Patel, B. K. C. (1998). Ammonia-hyperproducing bacteria from New Zealand ruminants. Appl Environ Microbiol 64, 1796-1804.

Benson, D., Lipman, D. J. \& Ostell, J. (1993). GenBank. Nucleic Acids Res 21, 2963-2965.

Collins, M. D., Lawson, P. A., Willems, A., Cordoba, J. J., Fernandez-Garayzabal, J., Garcia, P., Cai, J., Hippe, H. \& Farrow, J. A. E. (1994). The phylogeny of the genus Clostridium: proposal of five new genera and eleven new species combinations. Int $J$ Syst Bacteriol 44, 812-826.

Felsenstein, J. (1993). PHYLIP (Phylogenetic Inference Package) version 3.5.1c. Department of Genetics, University of Washington, Seattle, USA.

Fendrich, C., Hippe, H. \& Gottschalk, G. (1990). Clostridium halophilum sp. nov., and $C$. litorale sp. nov., an obligate halophilic and a marine species degrading betaine in the Stickland reaction. Arch Microbiol 154, 127-132.

Guangsheng, C., Plugge, C. M., Roelofsen, W., Houwen, F. P. \& Stams, A. J. M. (1992). Selenomonas acidaminovorans sp. nov., a versatile thermophilic proton-reducing anaerobe able to grow by decarboxylation of succinate to propionate. Arch Microbiol 157, 169-175.

Mclnerney, M. J. (1988). Anaerobic hydrolysis and fermentation of fats and proteins. In Biology of Anaerobic Microorganisms, pp. 373-415. Edited by A. J. B. Zender. New York: Wiley.

Magot, M. M., Ravot, G., Campaignolle, X., Ollivier, B., Patel, B. K. C., Fardeau, M.-L., Thomas, P., Crolet, J.-L. \& Garcia, J.-L. (1997). Dethiosulfovibrio peptidovorans gen. nov., sp. nov., a new anaerobic, slightly halophilic, thiosulfate-reducing bacterium from corroding offshore oil wells. Int J Syst Bacteriol 47, 818-824.

Maidak, B. L., Olsen, G. J., Larsen, N., Overbeek, R., McCaughey, M. J. \& Woese, C. R. (1996). The Ribosomal Database Project (RDP). Nucleic Acids Res 24, 82-85.

Nanninga, H. J., Drent, W. J. \& Gottschal, J. C. (1987). Fermentation of glutamate by Selenomonas acidaminophila sp. nov. Arch Microbiol 147, 152-157.

Paster, B. J., Russell, J. B., Yang, C. M., Chow, J. J. M., Woese, C. R. \& Tanner, R. (1993). Phylogeny of the ammonia-producing ruminal bacteria Peptostreptococcus anaerobius, Clostridium sticklandii, and Clostridium aminophilum sp. nov. Int $J$ Syst Bacteriol 43, 107-110.

Redburn, A. C. \& Patel, B. K. C. (1993). Phylogenetic analysis of Desulfotomaculum thermobenzoicum using polymerase chain reaction-amplified 16S rRNA-specific DNA. FEMS Microbiol Lett 113, 81-86. 
Rees, G. N., Patel, B. K. C., Grassia, G. S. \& Sheehy, A. J. (1997). Anaerobaculum thermoterrenum gen. nov., sp. nov., a novel, thermophilic bacterium which ferments citrate. Int $J$ Syst Bacteriol 47, 150-154.

Siebert, M. L. \& Toerien, D. F. (1969). The proteolytic bacteria present in anaerobic digestion of raw sewage sludge. Water Res 3, 241-250.

Smith, E. A. \& Macfarlane, G. T. (1997). Dissimilatory amino acid metabolism in human colonic bacteria. Anaerobe 3, 327-337.

Stankewich, J. P., Cosenza, B. J. \& Shigo, A. L. (1971). Clostridium quercicolum sp. n., isolated from discolored tissues in living oak trees. Antonie Leeuwenhoek J Microbiol Serol 37, 299-302.
Van de Peer, Y. \& De Wachter, R (1993). TREECON: a software package for the construction and drawing of evolutionary trees. Comput Appl Biosci 9, 177-182.

Winker, S. \& Woese, C. R. (1991). A definition of the domain Archaea, Bacteria and Eucarya in terms of small subunit ribosomal RNA characteristics. Syst Appl Microbiol 13, 161-165.

Zindel, U., Freundenberg, W., Rieth, M., Andreesen, J. R., Schnell, J. \& Widdel, F. (1988). Eubacterium acidaminophilum sp. nov., a versatile amino acid-degrading anaerobic producing or utilizing $\mathrm{H}_{2}$ or formate. Description and enzymatic studies. Arch Microbiol 150, $254-266$. 